\title{
A lógica do mercado e as retóricas de inclusão: articulações entre a crítica Frankfurteana e a Pós- Estruturalista sobre as novas formas de dominação
}

\author{
The market logic and inclusion rethorics: articulations \\ between the frankfurtean and the post-structuralist critique \\ about the new ways of domination
}

Maria de Fátima Vieira Severiano*

Universidade Federal do Ceará - UFC, Fortaleza, CE, Brasil

Pablo Severiano Benevides**

Universidade Federal do Ceará - UFC, Sobral, CE, Brasil

\begin{abstract}
RESUMO
O presente texto objetiva, a partir de uma articulação teórica entre o pensamento frankfurteano e o pós-estruturalista, produzir uma reflexão que contemple o modo como as novas formas de dominação vêm ganhando relevo nas sociedades atuais. Na medida em que ambas as perspectivas lançam suspeitas frente aos anúncios de que estaríamos assistindo a um tempo de maior liberdade, democracia e positivação das singularidades, buscamos realizar uma conjugação destas perspectivas com o propósito de efetivar uma análise crítica dos dispositivos/mecanismos que mascaram o exercício do poder nas formações sociais capitalistas contemporâneas. Para tanto, argumentaremos que a pretensa democracia e liberdade anunciadas pela Sociedade de consumo e pela Indústria Cultural estão a serviço da unidimensionalização do corpo social; do mesmo modo como certos discursos e políticas que militam pela inclusão social e escolar permanecem lidando com a alteridade sob o signo do estereótipo, captura e marginalização, suavizados pelo uso de figuras retóricas.
\end{abstract}

Palavras-chave: Sociedade de Consumo, Indústria Cultural, Unidimensional, Sociedades de Controle; Retóricas.

\begin{abstract}
The present text objectifies producing a reflection that contemplates the way new forms of domination have been standing out in the current societies based on a theoretical articulation between the Frankfurtean and PostStructuralist thought. As far as both perspectives raise suspicion towards the announcements that we would be seeing an era of greater freedom, democracy and activation of singularities, we search to achieve a conjugation of these perspectives with the proposal of enabling a critical analysis of the mechanisms/devices that conceal and disguise the exercise of power in contemporaneous capitalist social formations. To do so, we argue that the professed democracy and announced freedom by the Consumption Society and Cultural Industry are serving the unidimensionalization of the social organism; the same way certain speeches and policies that militate for the social and scholar inclusion remain dealing
\end{abstract}


with the alterity under the sign of the stereotype, capture and marginalization and softened by the use of rethorical figures.

Keywords: Consumption Society, Cultural Industry, One-Dimensional, Control Societies, Rethorics.

A utilização frequente e corriqueira de termos como "personalização", "singularidade", "liberdade de escolha", "diversidade", "reconhecimento minoritário", "inclusão social" etc. é característica marcante das formações discursivas contemporâneas, seja na esfera pública - meios de comunicação de massa, instituições educacionais, jurídicas e políticas -, seja na esfera privada - âmbito familiar e relações interpessoais. Isto, à primeira vista, parece anunciar uma época em que a individualidade, a liberdade e a pluralidade triunfaram definitivamente sobre $o$ mundo dito homogêneo $e$ autoritário das sociedades de massa do capitalismo industrial, encenando verdadeiras rupturas com as antigas relações de poder então vigentes.

Este estudo pretende, contudo, pôr em evidência o fato de que estes discursos que antevêem um tempo de maior respeito, liberdade e aceitação da diversidade na contemporaneidade podem consistir, precisamente, numa estratégia de manutenção da mesma lógica excludente que caracterizou as formações sociais capitalistas tradicionais. Para tal realização, utilizaremos uma abordagem transdisciplinar - pondo em discussão elementos teóricos da Escola de Frankfurt e referenciais analíticos dos pensadores Pósestruturalistas - com o propósito de dissolver e desarticular pretensos discursos libertários que caracterizam a estratégia de apaziguamento dos conflitos, típica das novas formas de controle vigentes no capitalismo tardio.

No âmbito dos meios de comunicação de massa, por exemplo, um dos principais argumentos que parece respaldar esta pretensa mudança na ordem das relações de poder diz respeito a uma suposta "liberdade de escolha" auferida aos consumidores ante uma multiplicidade de novos bens de consumo disponibilizados pelo mercado. Isto porque a sociedade contemporânea, ao incorporar as novas tecnologias, não mais se baseia na padronização dos bens de consumo típica das sociedades industriais, mas sim na "diferenciação" e "flexibilização" por segmentos de mercado, cada vez mais exigentes, capazes de produzir bens específicos e diversificados para cada público. As preferências distintivas por sempre novos estilos de consumo e a inovação técnica informatizada capaz de produzi-los são, neste sentido, concebidas como fatores de "libertação da individualidade" e de "diversidade cultural". Vejamos este discurso exemplar nas palavras de Featherstone (1990, p. 124) 
(...) as uniformidades declinam progressivamente com 1)as mudanças na capacidade técnica, que possibilitam maior variedade de produtos e maior diferenciação a ser incorporada nas séries de produção; e 2) a fragmentação crescente do mercado. Com efeito cada vez mais os indivíduos consomem produtos diferentes (...) $\mathrm{Em}$ decorrência, a cultura de consumo parece ser capaz de se aproximar mais da libertação da individualidade e das diferenças que sempre prometeu.

Neste caso, nossa preocupação maior reside nos processos de homogeneização produzidos atualmente pela mídia e pelo consumo, enquanto novas formas de opressão simbólica que, ao elidirem os reais processos de singularização e individuação, através de pseudoindividualidades de mercado, corrompem e enfraquecem princípios básicos de cidadania - lutas amplas pelos direitos de igualdade e liberdade - trocando-os seja pelos alardeados "direitos do consumidor", seja por participação "midiática interativa"; num suposto universo de múltiplas escolhas no qual "você decide": as cores preferidas da nova sandália hawaiana, quem merece sair do Big Brother, qual filme deverá ser exibido amanhã no Inter Cine, etc.

$\mathrm{Na}$ esfera política, principalmente quando articulada ao domínio educacional, as formas tradicionais e opressivas de exercício do poder apresentam-se como suplantadas por um novo modo de lidar com a alteridade marginalizada e excluída. Sob o signo das políticas públicas de inclusão social e escolar, da militância pela educação "multiculturalista" e de uma série de mecanismos outros que parecem valorizar e positivar a "diversidade" (negros, índios, ciganos, homossexuais, deficientes físicos e mentais etc.), o argumento permanece sendo o de que assistimos a um tempo em que a liberdade e a singularidade triunfaram sobre as cinzas das formas obsoletas e autoritárias de lidar com a "alteridade".

Contudo, nossa suspeita recai sobre o fato de que, nestes casos, o uso dos termos "diversidade" e "pluralidade de escolhas" parecem, ao contrário, funcionar de modo a respaldar e/ou camuflar as novas formas de controle social. Não estariam estes mecanismos, em verdade, buscando equalizar e dissolver as tensões que seriam características do encontro com a real "diferença", com o "outro" que não se deixa capturar pelas territorializações político-educacionais, agora transmutada e docilizada quando transposta para o signo pacificador e retórico da "diversidade"? Não buscariam, portanto, harmonizar a lógica do mercado à lógica da inclusão, na medida em que se travestem sob a roupagem de democratização e liberdade?

\section{A Escola de Frankfurt e a lógica da dominação}

A reflexão filosófica e cultural acerca das novas formas de dominação no capitalismo tardio foi empreendida, de forma pioneira, por alguns 
teóricos da Escola de Frankfurt, (ADORNO; HORKHEIMER, 1991; MARCUSE, 1982) a partir do início do século XX, no Instituto de Pesquisa Social, sediado em Frankfurt.

À luz do contexto histórico das duas grandes guerras mundiais, do triunfo do nazismo, do crescimento do stalinismo, do fracasso da classe trabalhadora européia frente à hegemonia capitalista e da emergência de uma cultura do consumo nas sociedades industriais avançadas da década de 60 , estes teóricos passaram a questionar a debilidade da razão frente à não-razão, apontando a fragilidade da resistência humana ante o totalitarismo, assim como as novas formas de poder oriundas da tecnologia, da mídia e do consumo massivo de bens materiais.

Adorno e Horkheimer (1991), na "Dialética do Esclarecimento", empreendem uma análise aprofundada dos elementos da racionalidade do mundo moderno para denunciá-los como uma nova forma de dominação, caracterizada pela previsibilidade e uniformização das consciências. A crítica filosófica da cultura realizada, neste contexto, demonstra o fracasso do programa do Esclarecimento, cuja promessa de salvar o mundo dos grilhões da superstição, da ignorância e do medo através da soberania do homem e de seu domínio sobre a natureza, resultaram frustrados.

O Esclarecimento, segundo esses autores, apresentou-se predominantemente em sua face coercitiva: $O$ homem, em sua tentativa de domínio sobre a natureza, findou por desenvolver um domínio totalitário sobre os próprios homens. A razão, ao pretender conciliar-se com a realidade, terminou por degradar-se a si mesma, transformando-se em uma razão encurtada, formalizada e fatídica: uma razão instrumental, mera justificação mistificadora do imediato, estranha à realidade concreta dos homens e ao seu mundo de vida. $\mathrm{O}$ único critério de verdade deste tipo de racionalidade passou a ser o seu valor operativo, ou seja, sua capacidade de eficácia na dominação da natureza. Isto porque a razão, ao alienar-se da reflexão sobre seus fins e valores, despoja-se de qualquer juízo ético, político ou valorativo sobre o homem, perdendo seus poderes de crítica e transformando-se num instrumento de legitimação da ordem dominante e de adequação do homem aos limites do fato estabelecido. Entretanto, vale ressaltar que não era à razão em si que estes autores criticaram, mas um tipo de racionalidade que passou a predominar principalmente após a consagração da epistemologia do Positivismo, no século XIX, enquanto a "legítima" representante da Ciência Moderna.

Sob este prisma, o conceito de "dominação" é então problematizado e modificado pelos teóricos frankfurtianos num duplo movimento: primeiramente no que concerne ao deslocamento da esfera restrita do trabalho para o amplo campo da cultura e, em segundo lugar, na metamorfose das formas explícitas para as formas também implícitas 
de dominação. Isto quer dizer que, para além da opressão e exploração visíveis das classes operárias da época do capitalismo industrial, o conceito passou a abranger, ainda, formas sutis de manipulação do pensamento e do desejo, capazes de produzir outro estilo de viver e perceber o mundo. Assim nos define Marcuse:

Domínio existe e atua sempre onde, no indivíduo, se encontram contidas as metas e finalidades e onde, nele, se encontram os modos de as alcançar [...] O domínio pode ser exercido pelos homens, pela natureza, pelas coisas - e pode até ser interior e realizado pelo indivíduo em si próprio, surgindo então na forma de autonomia (MARCUSE, 1980, p. 10)

É neste sentido que este autor nos fala de um triplo padrão de dominação: primeiramente dominação sobre o próprio eu, sobre sua própria natureza interna; segundo, dominação do trabalho conseguida por sobre indivíduos assim disciplinados e controlados; e terceiro, dominação da natureza exterior, ciência e tecnologia.

Portanto, considerando a complexidade e o relevo assumido pelos elementos culturais, até então concebidos pelo marxismo ortodoxo como um mero reflexo da esfera político-econômica (a exemplo da noção de que a luta de classe, assim como os mecanismos de dominação, ocorreriam essencialmente dentro do limites da esfera do trabalho), a Crítica da Cultura frankfurteana radicaliza a Crítica Social Marxista, estendendo suas análises para além dos muros das fábricas, alcançando os domínios da esfera da arte, do lazer, da linguagem, da religião, da sexualidade e dos meios de comunicação de massa.

A primazia das forças econômicas passa a ser, portanto, questionada por estes autores, sob o argumento de que, para se compreender o momento histórico prevalente a partir da década de 60 - a integração da classe trabalhadora no Ocidente e os aspectos políticos da racionalidade tecnológica - seria necessário uma reformulação da noção marxista ortodoxa de cultura como uma mera superestrutura a reboque da infraestrutura econômica, para concebê-la como uma esfera que possui um papel chave na vida privada e pública dos homens.

Deste modo, as características peculiares às formas de dominação nas sociedades pós-industriais transformam-se duplamente: a dominação, além de não mais se restringir à esfera econômica do trabalho - concebida enquanto exploração - e expandir-se de forma totalitária para dimensões da cultura e da vida cotidiana, passa a assumir também uma nova forma, não mais explícita e direta, mas implícita e sutil. Isto ocorreria por meio de uma hegemonia ideológica, que se utiliza da própria subjetividade humana e da gratificação dos desejos - através de instituições culturais tais como 
os meios de comunicação de massa, a educação e o lazer - para produzir identidades homogeneizadas, acríticas e em conformidade com a lógica capitalista. Assim nos esclarece Adorno:

\begin{abstract}
El papel del factor subjetivo se transforma en el proceso social total. Cuando se da una creciente integración, la relación superstructural-subestructura pierde su antigua fuerza. Cuando más son captados los sujetos por la sociedad, cuanto más completamente son determinador por el sistema, tanto más se mantiene el sistema, no simplemente por medio del uso de la coacción sobre los sujetos, sino también a través de ellos. (ADORNO, 1996, p. 19)
\end{abstract}

Portanto, este duplo deslocamento da dominação vigente nas sociedades do capitalismo industrial avançado ocorreria sob a forma de um duplo movimento: do econômico para o cultural, assim como das formas explícitas e concretas para as imperceptíveis e simbólicas; - que exigirá de nós uma nova atitude e um novo olhar, mais perspicaz e escrutinador, sobre as novas formas de controle social, visto que podem travestir-se de liberdade e democracia, a partir dos desejos do próprio sujeito em questão. E é justamente isto o que atualmente se observa com a expansão do domínio do mercado para a esfera cultural, a exemplo da perda do caráter transcendente da obra de arte e sua redução à mera mercadoria; da mecanização do tempo do ócio e sua transformação em lazer planejado pela indústria do turismo; da criação perpétua de "novas necessidades" no consumidor e do obsoletismo planejado dos produtos, conforme fins apriorísticos da indústria, além das promessas sempre incumpridas por "diferenciação" e "felicidade" veiculadas pela mídia.

Assim, as promessas de realização dos desejos humanos através da aquisição crescente de bens e serviços, e a "liberação" dos controles societários parecem concorrer, de forma inconteste, para o desaparecimento crescente de qualquer tipo de conflito que venha subverter essa ordem tão "confortável".

Como já nos advertira Marcuse (1982), referindo-se às sociedades afluentes da década de 60 - "Sociedade Unidimensional" -, estas se caracterizam pela abundância e diversidade de bens de consumo; nelas o potencial crítico é, em grande parte, abafado pelo próprio "progresso técnico" e suas conseqüentes promessas de "bem-estar comum". Aí se vive "uma falta de liberdade confortável, suave, razoável e democrática" (p. 23), desfazendo assim a tensão entre realidade e ideologia, explicitamente presente nas décadas anteriores. Também nela os interesses de grupos particulares passam a ser aceitos inquestionavelmente por todos, como sendo o interesse do "bem comum"; o que ocorre do mesmo modo com a transformação das necessidades - originariamente políticas da 
sociedade - em necessidades e aspirações individuais, reconciliando, desta forma, as forças oponentes ao sistema.

\begin{abstract}
Nas condições de um padrão de vida crescente, o não conformismo com o próprio sistema parece socialmente inútil (...) principalmente quando acarreta desvantagens econômicas e políticas tangíveis e ameaça o funcionamento suave do todo (MARCUSE, 1982, p. 32).
\end{abstract}

Deste modo, ocorre uma radical inversão: a lógica do mercado, cuja meta é o lucro e a expansão dos negócios, norteada por uma racionalidade instrumental e positivista, passa a apresentar-se sob a aparência de uma instância maternal e solícita, pronta para "realizar", de forma "plural" e ao mesmo tempo "individualizada", os mais caros ideais do homem; à "mercê" dos seus sonhos e desejos.

Como resultado, temos uma forma de dominação cada vez mais abstrata porque simula a liberdade dos desejos, apresentando o objeto de consumo destituído de suas determinações objetivas, aos moldes de uma tela projetiva onde todos os sonhos parecem se concretizar. É o primado absoluto do objeto sobre o sujeito, o qual decreta a dissolução do sujeito, apelando paradoxalmente para o seu imaginário e seus anseios por diferenciação.

Marcuse (1982, p. 65), já à sua época, reconheceu que a "realidade do pluralismo se torna ideológica e ilusória". Ao comentar a integração da classe trabalhadora ao sistema do capitalismo avançado, nos diz que este "pluralismo", na realidade, milita a favor da contenção da transformação social, solidificando o poder da totalidade social sobre o indivíduo, na medida em que está subordinado às "instituições competidoras" que promovem um "progresso tecnológico" dissociado dos interesses de emancipação do indivíduo (p. 64-5). Em conformidade com o pensamento de Marcuse, Adorno (1986, p. 64) também entenderá como um engodo a utilização do termo "pluralismo" para significar os supostos benefícios "propiciados" pelo capitalismo: "pela palavra pluralismo passa-se a supor a utopia como se ela já existisse: serve para o acalanto geral". Da mesma forma, as "distinções enfáticas" entre categorias de produtos visando a distinguir o "level“ de cada tipo de consumidor, tão caras aos defensores do "pluralismo" contemporâneo, já haviam também sido tematizadas por Adorno e Horkheimer (1991, p. 116):

Para todos algo está previsto; para que ninguém escape, as distinções são acentuadas e difundidas. O fornecimento ao público de uma hierarquia de qualidades serve apenas para uma quantificação ainda mais completa. Cada qual deve se comportar, como que espontaneamente, em conformidade com seu level, previamente caracterizado por certos sinais, e escolher a categoria dos produtos de massa fabricada para seu tipo. 
É a forma do fetichismo contemporâneo: a subjetividade do homem é transferida e alienada nos objetos para só então retornar a ele sob a forma de mercadoria. O que ocorre é que as "diferenças", tão aclamadas na contemporaneidade, continuam a ser fabricadas em série, só que, agora, de forma segmentada, pela produção industrial reordenada pelas novas tecnologias, cuja "flexibilidade" possibilita, ao mesmo tempo, diferenciar as pessoas por segmentos e homogeneizálas em seu interior.

O reinado desta suposta diferenciação fundada pelos objetos de consumo é reafirmado por Baudrillard (1970, p. 101) em seu conceito de "personalização" ao enfatizar que este é inaugurado, justamente, quando as diferenças reais e contraditórias entre as pessoas são abolidas, em nome das "diferenças personalizantes":

\begin{abstract}
As diferenças reais que marcavam as pessoas transformavam-nas em seres contraditórios. As diferenças "personalizantes" deixam de opor os individuos uns aos outros, hierarquizam-se todas numa escala indefinida e convergem para modelos, a partir dos quais se produzem e reproduzem com sutileza. De tal maneira que diferenciar-se consiste precisamente em adotar determinado modelo, em qualificar-se pela referencia a um modelo abstrato, a uma figura combinatória da moda e, portanto, em renunciar assim a toda a diferença real e toda a singularidade, a qual só pode ocorrer na relação concreta e conflitual com os outros e com o mundo.
\end{abstract}

\title{
I ndústria cultural e utopia
}

O conceito de "Indústria Cultural", desenvolvido por Adorno e Horkheimer, em 1947, por ocasião da publicação da obra "A Dialética do Esclarecimento", constitui-se em um elemento chave para esclarecer o deslocamento das formas de dominação para a esfera da cultura, assim como suas atuais formas de subjetivação, a qual se vale do mecanismo de reprodução ampliada das próprias necessidades e desejos dos indivíduos. Os referidos autores cunharam o termo "Indústria Cultural", a fim de substituir a expressão, então em uso, de "cultura de massa". Com o objetivo de negar ambos os termos da expressão - ou seja, nem "cultura" nem "massa" -, eles denunciaram 0 engodo de haver qualquer semelhança entre "cultura de massa" e democratização da cultura ao sublinhar o caráter compulsório e arbitrário da indústria cultural por eles concebida como "a integração deliberada, a partir do alto, de seus consumidores" (1986a, p. 92), na qual é suprimida tanto a rudeza espontânea da cultura popular que permitia resistir ao controle da "sociedade administrada" quanto à complexidade da "cultura erudita" e sua capacidade de transcendência ao mero factual. 
Adorno (1986a, p. 99) nos fala muito apropriadamente desta relação entre indústria cultural e autonomia:

A satisfação compensatória que a indústria cultural oferece às pessoas ao despertar nelas a sensação confortável de que o mundo está em ordem, frustra-as na própria felicidade que ela ilusoriamente Ihes propicia. O efeito de conjunto da indústria cultural é o de uma antidesmistificação, a de um antiiluminismo (anti-aufklärung); nela, como Horkheimer e eu dissemos, a desmistificação, a Aufklärung, a saber, a dominação técnica progressiva, se transforma em engodo das massas, isto é, em meio de tolher a sua consciência. Ela impede a formação de indivíduos autônomos, independentes, capazes de julgar e de decidir conscientemente. (p. 99).

Sua finalidade não seria, então, a de servir às massas, mas sim à racionalidade tecnológica e administrativa do grande capital, produzindo, assim, uma falsa mimese: fusão pacificadora entre indivíduo e sociedade, a partir da qual o particular (indivíduo) seria diluído na universalidade do social, de modo a instaurar o reino da positividade e o culto ao presente imediato como a única forma de realidade possível. A individuação, assim forjada, seria "pseudoindividuação", na medida em que não visaria à diferenciação entre indivíduo e sociedade, mas sim à homogeneização das consciências.

A afirmação de Adorno (1986a, p. 93) a respeito da indústria cultural mostra-se, neste contexto, bastante atual:

\begin{abstract}
... A indústria cultural inegavelmente especula sobre 0 estado de consciência e inconsciência de milhões de pessoas às quais ela se dirige, as massas não são, então o fator primeiro, mas um elemento secundário, um elemento de cálculo; acessório da maquinaria. O consumidor não é rei, como a indústria cultural gostaria de fazer crer, ele não é o sujeito dessa indústria, mas seu objeto.
\end{abstract}

Deste modo, parafraseando Adorno, entendemos que a conclamada "individualidade" auferida pelo mercado trata-se, na verdade, de um processo de "pseudo-individuação" em curso nas sociedades contemporâneas, que se pauta numa suposta diferenciação do indivíduo e tem por base a "eleição" (pretensamente livre) de estilos de consumo já previamente estandardizados e articulados pela lógica do mercado. Este, ao invés de operar sob a lógica bruta da exploração, serve-se fundamentalmente da lógica do desejo para promover uma identificação idealizada com seus objetos.

Nesse sentido, ressaltamos que o mais fundamental desta crítica não se reduz a uma mera denúncia da estandardização dos produtos pela indústria cultural, mas concerne, principalmente, à subsunção e dissolução do indivíduo na totalidade do social. Isto significa a ocorrência de uma espécie de reencantamento do mundo, uma fusão 
sujeito-objeto, na qual o homem somente adquire valor quando de sua identificação com as imagens de marca dos produtos "ofertados" pelo mercado, passando assim a confundir-se com este, desejando apenas aquilo que "deve" ser desejado.

Adorno e Horkheimer (1991) reafirmam tal questão ao enfatizarem que:

Na indústria, o indivíduo é ilusório não apenas por causa da padronização do modo de produção. Ele só é tolerado na medida em que sua identidade incondicional com o universal está fora de questão.

Entendida nessa perspectiva, o termo "unidimensionalidade", utilizado por Marcuse (1982), não se opõe à "pluralidade" ou à "diversidade", na medida em que estes últimos termos são compreendidos, unicamente, sob os parâmetros postos pela sociedade de consumo. Isto é, "pluralidade" e "diversidade" pertencem à esfera das imagens de marca agregadas ao objeto, enquanto "unidimensionalidade" refere-se à relação do sujeito com o objeto, ou seja, à unidimensionalização das vontades humanas em seu desejo de consumir. As estratégias do capital incrementado pelas novas tecnologias e pela publicidade nada mais fazem do que escamotear esta realidade, ofertando uma "pluridimensionalidade" de mercado. Mas a denúncia de uma "sociedade administrada" proferida pelos frankfurteanos não se referia meramente à homogeneização dos produtos do mercado, mas sim à convergência e subsunção de desejos, necessidades e comportamentos dos homens à lógica do capital. Que os produtos tenham se diversificado, seja em sua materialidade, seja em suas imagens, trata-se apenas de uma estratégia de marketing. O que importava aos teóricos da Escola de Frankfurt eram os processos de singularização e diversificação dos homens. Não podemos imputar os atributos do objeto ao sujeito a não ser pela via da fetichização, em que a utopia supostamente realiza-se através do mundo da mercadoria.

Portanto, o que está em questão é a perda da capacidade utópica do homem, de sua capacidade de transcendência do mero real/factual, responsável pelo desaparecimento da distância e da oposição crítica, necessárias aos processos de emancipação humana. Instala-se, por seu turno, uma lógica identitária em que indivíduo e sociedade devem a todo custo ser pacificados, harmonizados e suavizados em seus conflitos, produzindo uma unidimensionalização do real.

Entretanto, Lucien Goldman (1978) nos alerta que no decorrer de toda a história da humanidade o homem definiu-se, sobretudo como um ser de duas dimensões: o "real" e o "possível". Esta característica de bidimensionalidade humana é justamente o que explica que o homem além de ser o que é, caracterizado pelo real, não pode ser de 
todo definível, uma vez que seus limites extrapolam esse real numa perspectiva infinitamente maior do que o mero existente, superando a si próprio e projetando-se num futuro possível.

Ora, a capacidade de imaginar mundos utópicos partilha de uma tradição que, ao longo de milênios, pautou-se por compromissos humanitários. Conforme salienta Jacoby (2007, p. 10):

Das idéias greco-romanas de uma 'época de ouro' até as fantasias de reinos mágicos no séc. XIX, noções de paz, bem-estar e plenitude caracterizaram a utopia, no mais das vezes ligadas à fraternidade e ao trabalho coletivo.

Atualmente, o triunfo da racionalidade instrumental já anunciada há décadas pelos frankfurteanos reduz este ideário aos ditames do mercado, produzindo uma fusão entre realidade e possibilidades utópicas do homem.

Isto porque: enquanto o pensamento utópico, respaldado pela imaginação criativa, transcendia à mera factualidade do presente e tecia a crítica ao imediatismo do sistema, reconhecendo suas faltas e projetando-se em mundos futuros, temos na atualidade uma linguagem midiática que exacerba ao extremo os processos de idealização, apresentando a utopia como já realizada e o futuro não mais necessário, através das virtudes mágicas dos produtos e da adesão inconteste aos códigos do consumo. Aqui o objeto de consumo assume ares de perfeição, constituindo-se numa extensão do próprio sujeito, tornando-se, por isso mesmo, imune à crítica. Ideais heterônomos passam a substituir os ideais do indivíduo, num movimento regressivo que prescinde da criatividade e do pensamento crítico, produzindo uma falsa conciliação entre indivíduo e sociedade, numa pseudocompletude aconflitiva, resultando, em última instância, na perda da transcendência e na morte do desejo, dos projetos e das utopias. Preso às imagens repetidas à exaustão e à visão imediatista que fascina e seduz, a imaginação é conformada e enclausurada ao sentido que o produtor/publicitário/sistema deseja que seja percebido.

A relação parece ser inversamente proporcional: quanto mais as condições objetivas se distanciam da consecução da realização dos ideais utópicos, mais necessário se faz a produção de mecanismos de controle subjetivos que propiciem aos homens a ilusão de realização destes ideais. Exatamente por esta razão, quanto maior for a necessidade de instalação destes mecanismos de controle, mais escorregadio e eufêmico tornam-se os discursos que sustentam algumas políticas que se arvoram a concretizar um tempo de acolhimento aos excluídos, marginalizados e discriminados.

Daí nosso interesse, neste estudo, em analisarmos também como este travestismo pseudolibertário apóia-se, por diversas vezes, em figuras retóricas que fazem funcionar algumas políticas de inclusão 
social e, especificamente escolar, como formas de captura e constituição das alteridades sob o signo das mais distintas tipologias e constituições identitárias estereotipadas.

\section{A sociedade de controle e os teóricos da diferença}

A análise dos mecanismos de controle social subjetivo também foi alvo de reflexão crítica por parte dos chamados "Teóricos da Diferença" ou "pós-estruturalistas", a exemplo de Gilles Deleuze que, em sua obra: "Post-Scriptum Sobre as Sociedades de Controle" (1992), caracteriza de forma seminal a passagem das "sociedades disciplinares" para o que denomina de "sociedades de controle", apresentando como característica essencial a crise das grandes instituições de confinamento - a fábrica, a caserna, a escola, a prisão, o hospital, etc.

Deste modo, pretendemos tecer algumas articulações entre o diagnóstico frankfurteano de que estaríamos sob a égide de uma "sociedade administrada" ou "unidimensional" erigida a partir de uma pretensa democratização dos bens de consumo - cuja positivação de uma suposta pluralidade e singularidade se encontra sob as rédeas da lógica do mercado e não de forças políticas efetivamente emancipatórias - com a compreensão trazida por Deleuze (1992) de que estaríamos não mais em uma sociedade disciplinar, tal como descrita por Foucault, mas sim de controle.

A crise das grandes instituições apontada por Deleuze pode ser visualizada no constante reformismo no uso do qual se visa reestruturar as escolas (com métodos alternativos, políticas de inclusão e novas pedagogias progressistas), os hospitais psiquiátricos (com novas estruturas arquitetônicas, novos modos de compreender a relação médico-paciente), as organizações (com novos modelos de pró-atividade e com novos termos que surgem na gramática organizacional) etc. Isto porque, de alguma forma, sabemos, ou pressentimos, "que estas instituições estão condenadas, num prazo mais ou menos longo" (DELEUZE, 1992, p. 220).

Contudo, se esta crise das instituições é simultânea ao fracasso das formas disciplinares de exercício do poder como organizadoras do corpo social, isto deverá apontar para uma nova lógica de dominação que exige uma crítica distinta daquela realizada pelas sociedades disciplinares. Pois "a característica básica dessas sociedades [de controle] é dar a ilusão de uma maior autonomia mas, mesmo por isso, serem muito mais totalitárias que as anteriores" (GALO, 2005, p. 108).

Neste sentido, os mecanismos de controle seriam distintos dos disciplinares na medida em que os primeiros "são de curto prazo e de rotação rápida, mas também contínuo e limitado, ao passo em que a disciplina era de longa duração, infinita e descontínua" (DELEUZE, 1992, p. 225). E, naquilo que nos importa evidenciar neste estudo, 0 
exercício de um poder disciplinar encontra-se mais territorializado, melhor discernido e menos implícito do que aquele que observamos nas sociedades de controle.

Portanto, o desafio reside em encontrar formas de resistência em uma sociedade não mais disciplinar, ao passo em que o perigo consiste em utilizar armas obsoletas para combater antigos inimigos. Certamente, este era o sentido da metáfora utilizada por Deleuze "Os anéis de uma serpente são mais complicados que os buracos de uma topeira" (1992, p. 226) -, fazendo alusão a uma concepção economicista do poder que, por conseqüência, apontava para uma dada forma de resistência que entendemos ser inoperante na contemporaneidade. Isto ocorre precisamente porque as formas de resistência apregoadas pelo marxismo deveriam partir, fundamentalmente, da classe operária, a partir de uma conscientização frente às formas desiguais de apropriação do produto do trabalho e manipulação das condições materiais de produção da existência. Neste sentido, as demais "desigualdades" e formas de opressão seriam reflexos e reproduções da infra-estrutura econômica - o que nos permite ver, por exemplo, a escola como uma mera instância de reprodução das relações de produção (ALTHUSSER, 1974/1998). Na medida, portanto, que o poder é descentralizado, desempossado, dessubstancializado e as instituições encontram-se em vias de desarticulação, as formas de dominação sutilizam-se e surgem nos mais distintos contextos micro-políticos de modo a não poderem convergir em uma figura/instância concreta, palpável e instituída.

Neste sentido, autores como Foucault, Deleuze e Guatarri, em suas análises micro-políticas acerca do poder, apontam para outras formas de resistência que não são nem de ordem puramente economicista em semelhança à crítica realizada pela Escola de Frankfurt - nem da ordem unicamente molar, macro-política. Como salienta Costa (2009), no que tange a uma análise (e não a uma teoria!) foucaultiana acerca do poder, "talvez a guerra (e não a economia) viesse a constituir um analisador mais produtivo para as suas pesquisas genealógicas" (p. 28).

Sob estes aspectos, queremos chamar atenção para duas atitudes que, apesar de estarem aparentemente movida por fins distintos, acabam apresentando conseqüências semelhantes, dadas as "formas complexas de dominação política e de governo que funcionam estrategicamente, aquém e além do registro jurídico-político" (COSTA, 2009, p. 209-210). Atitudes reinantes em uma sociedade de controle, onde o "inimigo" não é mais facilmente corporificável na figura do patrão da fábrica, da diretora da escola ou do psiquiatra do manicômio.

A primeira delas já foi previamente esboçada, e consiste em supor que possamos utilizar as mesmas formas obsoletas de combate para 
uma guerra que requer outras estratégias. Isto se refere ao "certo esgotamento ou cansaço dos tradicionais modelos de referência que serviam de horizonte às lutas emancipatórias progressistas ou de esquerda" (COSTA, 2009, p. 209). Nas palavras de Galo (2005, p. 111), "não podemos apontar uma adaga para combater uma ogiva nuclear" - o que equivaleria, em certa medida, a buscar eleger centros de onde emana o poder e entender que suas micro manifestações não passam de uma "reprodução" do que ocorre neste centro.

Precisamente por ser mais camaleônico que os mecanismos disciplinares, os mecanismos de controle possuem a aparência de acolherem as lutas, os manifestos, as queixas e as insatisfações que Ihes são apresentados. Neste aspecto, os próprios discursos que outrora funcionavam como resistência - seja no âmbito da educação, da cultura ou mesmo da política em geral - hoje em dia podem facilmente ser cooptados pela lógica reformista, compensatória e modular das sociedades de controle. É exatamente amparando, de forma aparentemente paradoxal, discursos progressistas e/ou de esquerdas e discursos conservadores que, por exemplo, as "novas igrejas" apresentam estratégias mais "contemporâneas" para atrair o público jovem (seja através da música "moderna", das construções arquitetônicas "estilizadas" ou da aparência estética apresentada pelos novos "padres-estrelas"); que as escolas se munem de políticas de inclusão e, quando muito, de novos métodos pedagógicos destinados a alunos que ganharam a extensa nomenclatura de "portadores de necessidades educativas especiais", com a finalidade de serem úteis e de se harmonizarem com a sociedade na qual vivem; que os hospitais psiquiátricos cedem lugar aos CAPSs, onde a meta passa a ser da cura de uma patologia à ressocialização das condutas (novamente com a finalidade integrativa durkheimiana); ou, mesmo, que os estudantes líderes de CAs e DCEs "pedem estranhamente para serem 'motivados', e solicitam novos estágios e formação permanente" (DELEUZE, 1992, p. 226), sem terem a ciência "a que estão sendo levados a servir" (idem) - a saber, a lógica paradoxal das sociedades de controle que tendem a neutralizar as resistências e a perpetuar a "formação" ao infinito.

Uma segunda atitude, igualmente problemática, consiste na suposição de que a crise das instituições de confinamento disciplinares são coincidentes com a emergência de um tempo caracterizado por uma maior liberdade e autonomia, e que, finalmente, estaríamos vivenciando uma era em que a diversidade e a pluralidade de valores, crenças, etnias, estilos de vida etc. coabitariam em um mundo de respeito e consideração mútua entre todos os seres humanos.

Se, na primeira atitude, a resistência é inoperante, na segunda ela se faria desnecessária. 
Como conseqüência da adoção desta atitude, suporíamos, ainda que de forma propedêutica e lenta, estar vivendo em um tempo onde a democratização do ensino e o paradigma da "transparência" - posto em movimento pelos "avaliadores externos" que investigam as "metas" a serem alcançadas pelas escolas - funcionariam em prol de uma escola "de qualidade" e mais próxima de sua comunidade, prestando contas a ela. Isso nos impediria, então, de enxergar esse fenômeno como uma forma de exercício de controle da sociedade sobre a escola que, uma vez fundida a esta, não manteria a distância e a tensão necessárias a uma crítica da sociedade (BATISTA, 2000). I gualmente, a partir desta atitude, teríamos a impressão de que, no âmbito das empresas, "o princípio modulador 'salário por mérito"” (DELEUZE, 1992), ao tender a substituir a punição salarial pelo reforço, anunciaria um tempo de maior oportunidade ao trabalhador - e não veríamos isso como uma forma de estimular a rivalidade horizontal para neutralização de um confronto vertical e hierárquico. Por fim, suporíamos que todas as políticas e discursos de inclusão social e escolar - desde o AEE (Atendimento Educacional Especializado), ao "Bolsa Família" - seriam o prenúncio de um tempo de inclusão dos mais necessitados para que possamos concretizar verdadeiramente (e não falsamente, como alguns discursos "pósmodernos" entendem ter ocorrido na Modernidade) os ideais iluministas de universalidade, individualidade e autonomia.

Todavia, ao estabelecerem um deslocamento de ênfase para noções como "diversidade" e "singularidade", estas formações discursivas contemporâneas, uma vez subsidiadas por uma lógica de mercado pretensamente pluralista recaem sob o signo daquilo que Duschatzky e Skilar (2001, p. 120) entenderam como sendo as "retóricas sobre a diversidade". Estas não passariam de

(...) palavras suaves, de eufemismos que tranqüilizam
nossas consciências ou produzem a ilusão de que
assistiríamos a profundas transformações sociais e culturais
simplesmente porque elas se resguardam em palavras da
moda (...) aliados de certos discursos e práticas culturais tão
politicamente corretas como sensivelmente confusas.
(DUSCHATZKY; SKILAR, 2001, p. 120).

Argumentaremos, portanto, que estas figuras retóricas consistem numa mescla, ou num tomada simultânea de ambas as atitudes acima descritas, que geram a inoperância das formas de resistência (na medida em que discursos progressistas são traduzidos a partir daqueles "politicamente corretos") e sua extinção (a partir da suposição de que estas "profundas transformações sociais" já estão sendo realizadas, e bastaria reafirmá-las) em uma sociedade de controle. 
Assim, chegamos a um ponto de articulação entre os frankfurteanos e os pós-estruturalistas. A utilização de formas obsoletas de combate, assim como a crença na realização de um tempo de maior liberdade e respeito às diferenças desconhece o que há décadas alertaram estes autores acerca das novas formas de dominação. Na medida em que esta cria "a falsa identidade do universal e do particular" (ADORNO; HORKHEIMER, 1991, p. 114), em que tudo é integrado, incluído e nada é negado (a não ser a própria liberdade de criticá-la), estas formas de dominação se travestem, pelas figuras retóricas, em formas de acolhimento, inclusão e aceitação - o que aparenta, portanto, justificar a afirmação de que vivemos em uma sociedade cujos ideais libertários já estariam, se não realizados, na iminência de serem.

Neste ponto, buscamos com Marcuse (1982, p. 88), advertir acerca da ainda vigente "consciência feliz", na qual toda possível transcendência é assimilada pelo sistema, não existindo mais conflitos absolutos, uma vez que é justamente em nome da "liberdade", do "sempre novo", das "múltiplas escolhas" que se exerce o controle sobre as consciências. Entretanto, nos alerta Marcuse (1982, p. 28):

A eleição livre dos senhores não abole os senhores ou os escravos. A livre escolha entre ampla variedade de mercadorias e serviços não significa liberdade se esses serviços e mercadorias sustêm os controles sociais sobre uma vida de labuta e temor - isto é, se sustêm alienação. E a reprodução espontânea, pelo indivíduo, de necessidades superimpostas não estabelece autonomia; apenas testemunha a eficácia dos controles.

Adorno e Horkheimer (1991, p. 126) já haviam também advertido para a ilusão do "novo" na era da indústria cultural, na qual,

(...) a máquina gira sem sair do lugar. Ao mesmo tempo que já determina o consumo, ela descarta o que ainda não foi experimentado porque é um risco. (...) Nada deve ficar como era, tudo deve estar em constante movimento. Pois só a vitória universal do ritmo da produção e reprodução mecânica é a garantia de que nada mudará, de que nada surgirá que não se adapte.

E é precisamente girando neste frágil terreno que ampara os discursos contemporâneos - e em busca de novas formas de capturas, sempre no intuito de serem mais sutis porque mais eficazes - que as novas síndromes, as novas "dislexias", os novos guetos, as novas siglas, as novas leis, os novos produtos da "Indústria Cultural" e os novos termos "politicamente corretos" precipitam-se nas instâncias jurídicas, educacionais, políticas, midiáticas, culturais, 
econômicas e mesmo cotidianas, sob o signo das retóricas sobre a diversidade.

\section{As retóricas sobre a diversidade e a neutralização das resistências}

Da mesma forma que a crítica frankfurteana lançou severas suspeitas sobre os mecanismos de controle engendrados pela Indústria Cultural, desvelando um terreno fértil para pesquisas (por exemplo, sobre o poder das imagens midiáticas e publicitárias na constituição das subjetividades contemporâneas) a crítica pós-estruturalista pôs em relevo outro tipo de mecanismo de controle, desta feita, concernente às formações discursivas, que, antes de ter inserção num plano meramente lingüístico e analítico, traz profundas conseqüências para a vida concreta dos indivíduos.

Autores como Veiga-Neto (2005/2001), Ferre (2001), Duschatzky e Skilar (2001), ao levantarem uma suspeita relativa aos modos de como as políticas de identidade, os discursos sobre inclusão e uma série de estudos culturais lidam com a alteridade, apontam para a possibilidade de estes discursos, que supostamente se apresentam como progressistas e/ou de resistência, sejam meramente retóricos. Ora, uma vez subsidiados pelos "filósofos/teóricos da diferença Foucault, Guattari, Deleuze, Derrida - o que estes autores procuram investigar é, precisamente, se estamos vivendo de fato em um tempo em que a diferença e a singularidade são efetivamente positivadas pelas "retóricas da moda" (DUSCHATZKY; SKILAR, 2001, p. 119).

Tendo como solo fértil para seu aparecimento as sociedades de controle - cuja sutileza e virtualidade dos mecanismos de dominação apontam para um suposto tempo de extinção dos preconceitos, da violência e da intolerância - postulamos que as retóricas da moda consistem no maior signo da instabilidade discursiva que vivenciamos.

Conforme descrito por Bauman (2001), uma das características principais da Modernidade é sua busca desenfreada pela dissolução ou seja, a transformação dos sólidos em líquidos. "Dissolução" e "liquefação" são metáforas que fazem alusão à potencia devastadora da Modernidade que age no sentido de arrancar e jogar ao vento as antigas pilastras que sustentavam os valores com base na tradição. Exemplo emblemático desta atitude consiste na dúvida radical cartesiana esboçada no "Discurso sobre o método" (1637) e nas "Meditações Metafísicas" (1641), onde o filósofo propunha a si "rejeitar como absolutamente falso tudo aquilo em que pudesse encontrar a menor dúvida" (DESCARTES, 1637/2001, p. 41).

Ora, se, mesmo na obra "Modernidade Líquida" (2001), Bauman nos evidencia que a pretensão de liquefação era subsidiada por uma finalidade distinta, a saber, erigir sólidos mais resistentes, isto está, ainda, em conformidade com a atitude de Descartes que rejeita tudo 
o que é possível pôr em dúvida com o fim de "verificar se restaria, depois, alguma coisa em minha crença que fosse inteiramente indubitável" (DESCARTES, 1637/2001, p. 41). Contudo, a irrealização dos ideais iluministas e o fracasso de Descartes em termos de alcançar o produto sólido a que buscava (a verdade racional) aliado ao sucesso do seu processo de busca (o método) produzem toda a instabilidade discursiva que caracteriza as formações discursivas contemporâneas. Assim, o estado de "anomia" - conforme descrito por autores como Durkheim (1922/1973) e Mannhein (1971), a saber, como uma inoperância dos mecanismos de controle - consiste no signo da dissolução dos valores e numa verdadeira perda de sentido para a direção humana. O paradoxo, contudo, é que não há a total ausência e nem uma onipotente não-representação e nãovisualização dos valores, das normas, do sentido e da verdade, mas tão somente certo enfraquecimento de sua força - o que leva, ao contrário, não a um abandono desses valores, mas a uma busca incessante de definição, identificação, classificação, culturalização e delimitação dos grupos, das identidades e das referências culturas e sociais. E é precisamente sob a fertilização deste solo que brotam as retóricas sobre a diversidade, ou retóricas da moda.

Em verdade, não é necessário o esforço de uma reflexão mais elaborada para simplesmente percebemos as manifestações dessa instabilidade discursiva que presenciamos. Signo deste fenômeno é, por um lado, o surgimento de "novas" patologias, "novos" transtornos, "novas" dislexias - muitas vezes estampados a partir de uma sigla que condensa a extensa nomenclatura correspondente que invadem os "saberes" médico, psicológico, psiquiátrico e pedagógico. Percebemos, também, a mudança de termos que designam os novos "guetos", com suas características identitárias tão profundamente confusas quanto pretensamente purificadas - como é - caso do deslocamento de termos para designar os grupos cujas atitudes sexuais encontram-se à sombra da norma: "gays" - "gls" "glsbtt" (cuja atitude correspondente não é mais o "homossexualismo" ou a "homossexualidade", mas a "homoafetividade"), cada vez mais entendendo a "diversidade" sexual e a singularidade de cada sujeito em relação ao sexo como sendo fruto daquilo que cada um é em sua "natureza" e "essência".

Contudo, talvez o fenômeno que mais nos chame atenção em todo esse "travestismo discursivo" (DUSCHATZKY; SKILAR, 2001, p. 119) resida precisamente no mecanismo compensatório em que assumem as figuras retóricas, a saber, como uma "proteção lingüística" (VEIGA-NETO, 2001, p. 108) que age como se quiséssemos "expiar uma culpa" (idem). Isto é evidente quando evitamos utilizar determinadas palavras para designar grupos que efetivamente ainda são excluídos pela lógica capitalística ("aidético", "negro", "velho", "deficiente") e buscamos construir outros termos ("soropositivo", 
"afro-descendente", "melhor idade", "portador de necessidade especial") supostamente mais acolhedores a estes grupos estereotipados e marginalizados. Estes fenômenos, por vezes - e nisto consiste o cerne desta crítica! - não consistem em mudanças cotidianas e lentas, mas em reformulações jurídicas imediatas e instantâneas que indicam o termo adequado a ser usado em referência às identidades em questão. O perigo que estes atos jurídico-linguísticos acarretam é precisamente a produção da ilusão de que a mera substituição terminológica já seria o suficiente para implicar num novo trato com a alteridade em questão.

Ora, a denúncia que fazemos é, portanto, que a nomeação consiste num exercício de poder por parte de quem reparte o corpo social em função da norma. Portanto, longe de ser um ato de cuidado, respeito e acolhimento frente às singularidades excluídas, as "políticas de inclusão" e as "retóricas da moda" pressupõem uma ação prévia da norma que segmenta os sujeitos como inseridos sob seu corpo (os normais) ou sob sua sombra (os anormais). Portanto, a "diversidade" positivada pelas figuras retóricas faz, por um lado, parecerem "naturais" ou "espontâneas" as diferenças individuais e culturais que, em verdade, são implicitamente significadas pelos mecanismos de partição que a norma realiza em um grupo, ou no corpo social em geral. Sobre isso, atenhamo-nos às palavras de Veiga-Neto (2001, p. 115):

A norma, ao mesmo tempo em que permite tirar, da exterioridade selvagem, os perigosos, os desconhecidos, os bizarros - capturando-os, tornando-os inteligíveis, familiares, acessíveis, controláveis -, ela permite enquadrá-los a uma distância segura a ponto que eles não se incorporem ao mesmo. Isso significa dizer que, ao fazer de um desconhecido um conhecido anormal, a norma faz desse anormal mais um caso seu. (...) O anormal é mais um caso, sempre previsto pela norma.

Este é precisamente o ponto de articulação entre a crítica frankfurteana e a crítica trazida pelos autores filiados aos "filósofos da diferença". A "diversidade" está para a efetiva "diferença" e singularidade positivada por estes autores assim como a suposta libertação apregoada pela Sociedade de Consumo estaria para os valores de autonomia e emancipação, tão caros aos pensadores da Escola de Frankfurt.

Deste modo, se a "diversidade" positivada pelos discursos inclusivos constitui-se num artifício retórico para camuflar a designação de "anormalidade" que o termo efetivamente busca significar, e se a liberdade apregoada pela Sociedade de Consumo consiste em um artifício da lógica de mercado que visa esconder as finalidades unidimensionalizantes destes mecanismos de dominação, o propósito 
destes fenômenos contemporâneos parece, a ambas as perspectivas em questão, muito claras: desarticular as formas de resistência e/ou utopias.

Vinculados pela vertente filosófica da "ontologia do presente" (COSTA, 2003) ambas correntes de pensamento, apesar de suas distintas posições epistemológicas e políticas em uma série de aspectos, possuem em comum a interrogação e inquietação constantes acerca da atualidade, assim como a reflexão crítica sobre o campo de experiências possíveis no presente. Neste estudo em específico, interrogam o sujeito em suas relações com a dimensão da cultura, investigando possibilidades de autonomia em meio às novas formas de produção e ocultamento do poder.

A suspeita, portanto, de que a singularidade e a diferença não estão efetivamente sendo presenciadas como "linhas de fuga" e/ou como evidência de realização de princípios emancipatórios (mas como anormalidades, sob os padrões previsíveis dos dispositivos políticoeducacionais capitalistas), assim como de que a liberdade e a autonomia não estão, de fato, sendo concretizadas em nossa sociedade, tal como conclamam de forma tão veemente alguns apologistas "pós-modernos" e os defensores da Sociedade de Consumo, traz consigo uma série de razões que nos levam a crer que existem semelhanças teóricas entre ambas as perspectivas que podem, a expensas de suas diferenças teóricas indissolúveis, funcionar como um aprimorado instrumento de denúncia frente às armadilhas camaleônicas de uma sociedade de controle/administrada, incapazes de serem desarticuladas pelos tradicionais discursos e/ou imagens que se travestem de progressistas e revolucionárias.

Sem o reconhecimento dessas novas formas de controle só resta aos homens aceitar os mecanismos/dispositivos de dominação como uma "fatalidade" ou uma "naturalidade", donde advém o sentimento contemporâneo de uma indeterminabilidade difusa, quando na realidade estamos mais determinados do que nunca. Essa indeterminabilidade difusa foi denominada por Adorno (1986b, p. 71) como "o onipresente éter da sociedade":

(...) este é, porém, tudo, menos etéreo: pelo contrário, ele é o ens realissimum [o que há de mais real]. Na medida em que ele parece abstrato, essa sua abstração não é culpa de um pensamento especulativo, obstinado e desligado da realidade, mas sim da relação de troca, da abstração objetiva a que o processo da vida social obedece. O poderio de tal abstração sobre os homens é mais concreto do que o de qualquer instituição individual que, tacitamente, se constitua, de antemão, de acordo com o sistema e o inculque nos homens. A impotência que o indivíduo experimenta diante do todo é a drástica expressão disso. 


\section{Referências Bibliográfias}

ADORNO, T. W. Indústria Cultural. In: COHN, G. Theodor Adorno: Sociologia. São Paulo: Ática, 1986a, p. 92-107. . Capitalismo Tardio ou sociedade industrial? In: COHN, G. Theodor Adorno: Sociologia. São Paulo: Ática, 1986b, p. 62-75. $\overline{1} 9 \overline{9} \overline{6}$. . Introducción a la Sociología. Barcelona, Espanha: Gedisa,

ADORNO, T. W.; M. HORKHEIMER. Dialética do Esclarecimento. 3. ed. Rio de Janeiro: Jorge Zahar, 1991.

ALTHUSSER, L. I deologia e aparelhos ideológicos do Estado. 7a Ed. Rio de Janeiro: Graal, 1998.

BATISTA, S. Teoria Crítica e teorias educacionais: uma análise sobre o discurso da educação. Educação \& Sociedade, Campinas, SP: Cedes, v. 21, n. 73, p. 182-204, dezembro de 2000.

BAUDRILLARD, J. A Sociedade de Consumo. São Paulo: Livraria Martins Fontes, 1970.

BAUMAN, Z. Modernidade Líquida. Rio de Janeiro: Jorge Zahar, 2001.

COSTA, S. Para problematizar nossa (in) atualidade: pensando um agenciamento metodológico entre Foucaul e Deleuza. In: MATOS, K. (Org.). Movimentos Sociais, Educação Popular e Escola: a favor da diversidade, Fortaleza, UFC, p. 158-175, 2003.

Biopolítica, Governamentabilidade e Educação. Belo Horizonte: Autêntica, 2009.

DELEUZE, G. Conversações. Rio de Janeiro: Ed. 34, 1992.

DESCARTES, R. (1637) O discurso do método. São Paulo: Martin Claret, 2001.

$\overline{1988 .}$

(1641) Meditações Metafísicas. São Paulo: Nova Cultura,

DURKHEIM, E. Educación y Sociologia. Buenos Aires: Editorial Shapire, 1973.

DUSCHATZKY, S.; SKILAR, C. O nome dos outros. Narrando a alteridade na cultura e na educação. In: LARROSA, J.; SKILAR, C. (Orgs.). Habitantes de Babel: Políticas e poéticas da diferença. Belo Horizonte: Autêntica, 2001, p. 119-138.

FEATHERStOne, M. Cultura de Consumo e Pós-Modernismo. São Paulo: Studio Nobel, 1995.

FERRE, N. Identidade, diferença e diversidade: manter viva a pergunta. In: LARROSA, J.; SKILAR, C. (Orgs.). Habitantes de Babel: Políticas e poéticas da diferença. Belo Horizonte: Autêntica, 2001, p. 195-214.

GALO, S. Deleuze e a Educação. Belo Horizonte: Autêntica, 2003. GOLDMAN, L. Epistemologia e Filosofia Política. Lisboa: Presença, 1986.

JACOBY, R. I magem I mperfeita: pensamento utópico para uma época antiutópica. Rio de J aneiro: Civilização Brasileira, 2007. 
MANNHEIM, K. Libertad y Planificación Democratica. México: Editorial Fondo de Cultura Economica, 1971.

MARCUSE, H. Psicanálise e política - o fim da utopia. 2.ed. Lisboa, Portugal: Moraes Editores, 1980.

- A I deologia da Sociedade Industrial: O Homem Unidimensional. 6a ed. Rio de Janeiro, Zahar, 1982.

VEIGA-NETO, A. Incluir para excluir. In: LARROSA, J.; SKILAR, C. (Orgs.). Habitantes de Babel: Políticas e poéticas da diferença. Belo Horizonte: Autêntica, 2001, p. 105-118.

\section{Endereço para correspondência}

Maria de Fátima Vieira Severiano

Avenida Rui Barbosa, 640/401, CEP 60115-220, Fortaleza - CE, Brasil

Endereço eletrônico: fatimasev@terra.com

Pablo Severiano Benevides

Avenida Rui Barbosa, 640/401, CEP 60115-220, Fortaleza - CE, Brasil

Endereço eletrônico: pabloseveriano@hotmail.com

Recebido em: 12/03/2010

Aceito para publicação em: 15/04/2010

Acompanhamento do processo editorial: Ariane P. Ewald e Jorge Coelho Soares

\section{Notas}

*Doutora, Professora Associada II da Universidade Federal do Ceará - UFC, Fortaleza, CE, Brasil

**Mestre, Professor Assistente I da Universidade Federal do Ceará - UFC, Sobral, CE, Brasil 